\title{
RESPONSABILIDAD SOCIAL DEL INTELECTUAL Y OTRAS RESPONSABILIDADES
}

\section{Tomás A. Vásquez A.}

Estanislao Zuleta fue ante todo un intelectual. Un hombre que "se atrevió a pensar por sí mismo". Que elogiando "aguerridamente" las dificultades y los escollos, desafiando las adversidades propias de nuestro medio cultural, logró abrirse paso conquistando un merecido lugar entre los pensadores colombianos del presente siglo.

Su estilo no era prestado. Muchas cosas le eran propias: su hablar fluido con un acento y tonalidad cotidianos, tan sencillos que contrastaban con la profundidad y riqueza de lo que exponía. Tal vez esto le valió para que fuera considerado como un excelente conferencista y un extraordinario conversador.

Es cribía casi como hablaba y viceversa, pues para el no existían barreras entre la filosofía y la vida. Así lo ratifica su propio hijo al decir que "su trayectoria estuvo marcada por una alianza, casi desconocida, entre la conducta y el pensamiento". Pensamiento este que él mismo supo alimentar con una persistente y placentera autoexigencia, encontrando en los griegos, en Kant, Hegel, Nietzsche, Freud, Marx y Sartre, las ideas que sabiamente supo asimilar para comprender y ayudarnos a comprender nuestro difícil momento his tórico.

Estanislao Zuleta es considerado, en parte, tributario de la filosofía francesa contemporánea, fundamentalmente de Sartre, para quien el pensamiento está directamente conectado, por principio y por vocación personal, con la problemática social y política. De allí que la idea del intelectual comprometido -"engagé"- que el defendió, sea el paradigma del hombre de pensamiento y letras que Estanislao Zuleta fue.

\section{LA RESPONSABILIDAD SOCIAL DEL INTELECTUAL}

\section{NUESTRO MOMENTO DE CRISIS AGRAVADA NOS EXIGE QUE PENSEMOS EN LARESPONSABILIDAD SOCIAL DEL INTELECTUAL.}

Siempre se ha creído que la responsabilidad del intelectual es un comportamiento puramente compulsivo, que el intelectual no tiene responsabilidad sino con el conocimiento, con la investigación, con el pensamiento y que sus efectos sobre la historia se derivan de su integridad como pensador y no de sus propósitos políticos. De alguna manera es así. Quiero reconocer que hay efectos de la cultura que están muy alejados de los propósitos conscientes de un autor y que pueden

\footnotetext{
*Entrevista con Estanislao Zuleta.

** Profesor de la Facultad de Educación, Universidad Pedagógica Nacional. 
ser incluso más profundos y más eficaces que aquellos que son conscientemente buscados. Por ejemplo, uno puede pensar, considerando el concepto de intelectual en los términos más amplios posibles, más o menos hegelianos, que incluían el pensamiento todo y las manifestaciones de la cultura, para tomar el caso colombiano y un ejemplo sencillo: consideremos que algunos de los poetas que fueron muy populares, y en cierto modo lo siguen siendo, no tenían propósitos políticos. Por ejemplo, pienso en el Nocturno III de Silva, pienso en algunos poemas de Barba Jacob. Sin embargo, su manera de valorar la vida, de considerar el amor, la muerte, el destino, tiene un efecto disolvente sobre la cultura patriarcal católica de la sociedad colombiana, probablemente más poderoso que la obra de Vargas Vila que se proponía directamente anticlerical...

\section{O SEA QUE ES LA OBRA DE ARTE SOLA LA QUE REPERCUTE} INDIRECTAMENTE EN LA SOCIED AD SIN LA NECESIDAD DE QUE SU AUTOR PROCLAME DIRECTAMENTE SUS EFECTOS?...

Sí, porque Vargas Vila alerta más fácilmente la defensa, mientras un Barba Jacob no alerta a nadie. Apela a una vivencia íntima extraña al pensamiento del catolicismo de entonces y de las ideas dominantes. En ese sentido, puede uno decir que efectivamente, en un intelectual, un pensador, un poeta, son muy independientes sus efectos reales de sus propósitos conscientes.

Eso ya lo sabía Marx cuando saludaba la obra de Balzac como una obra en la que había aprendido más -dijo alguna vez- que en todos los economistas e historiadores franceses juntos. Sin embargo, Marx no ignoraba que Balzac era católico y monarquista. En el prólogo de La Comedia Humana, Balzac dice que toda su obra se basa en dos verdades que son etemas: la monarquía y el catolicismo. Pero Marx no le prestaba atención a sus propósitos directos sino a los efectos reales de su pensamiento y de su trabajo intelectual.

Existe, pues, la posibilidad de darle a esa pregunta una respuesta en un sentido que algunos podrían llamar escapis ta: el intelectual no tiene responsabilidad sino con el rigor de su pensamiento, con el rigor de su obra, con el desarrollo de su trabajo. Y los efectos sociales que esta obra tiene no proceden de sus propósitos políticos conscientes. Ahora, esto no es más que una cara del problema.

ERNESTO SABATO HABLA DE LAS DOS CARAS DEL ESCRITOR: LA DEL INDAGADOR DE LOS CONFINES DE LA CONDICION HUMANA Y LA OTRA, LA DEL CIUDADANO COMPROMETIDO CON LA REALIDAD TRAGICA DE AMERICA LATINA

En nuestro continente latinoamericano hemos tenido experiencias amargas. Leí en una revista francesa, dedicada toda a Argentina en el momento de la dictadura militar, un ensayo que me pareció curioso. Un psicoanalista argentino hacía una especie de autocrítica: ¿Cómo es posible -decía- que mientras esto se nos estaba viniendo encima nosotros estuvimos recluidos en nuestros consultorios atendiendo a nuestros pacientes y nunca examinamos los fenómenos sociales argentinos, los 
problemas de la sensibilidad y de la mentalidad, ni el tango, ni el peronismo, ni la religiosidad, y sólo cuando tuvimos que tomar el avión hacia el exilio comenzamos a pensar en Argentina? ¿No habría sido más responsable pensar a tiempo en Argentina? Esto me parece muy interesante. Eso sería una réplica.

Ambas cosas son ciertas. Yo no creo que un intelectual colombiano pueda hoy darse el lujo de no pensar en la violencia. ¿Acaso no le dice nada que el año 88 sea el año de las masacres? ¿No le dice nada la combinación curiosa de libertades democráticas mezcladas y entreveradas en toda la nación y en todas las capas de la sociedad con el terror? ¿Cómo puede uno vivir en Colombia y no preguntarse si en verdad hay libertad de prensa en el sentido de que el gobiemo no es tá cerrando periódicos, ni siquiera los del Partido Comunista ni los que ponen en cuestión el sistema mismo? El gobierno no está destituyendo profesores y maestros por sus ideas. En cieno sentido hay libertad de cátedra. Pero están siendo amenazados, están siendo as esinados, han tenido que huir. Es verdad que hay cierta libertad de asociación, es decir, los sindicatos no son cerrados por sus tendencias políticas, ni sus licencias les son retiradas por los mismos motivos. Pero sus dirigentes son asesinados. Entonces, hay una libertad política habitada por el tenor. ¿Cómo no pensar un fenómeno de esos?

\section{Y CON RELACION AL FILOSOFO ¿CUAL SERIA SU RESPONSABILIDAD SOCIAL?}

Si nos querernos reducir un poco al problema filosófico, porque intelectual es demasiado genérico. Los filós ofos siempre han sido, digámoslo así, polifilósofos. Es decir, si uno se pregunta de qué habla Platón es mejor que se pregunte de qué no habla. Lo mismo puede pasar con Aristóteles. Descartes habla de las pasiones, de los meteoros, de física, de geometría analítica -des de luego, es su fundadorpero también habla de metafísica, de problemas sociales, etc. ¿De qué no habla Kant? Hasta de la Revolución Francesa, desde luego. No podría ser ajeno a ese problema. Tiene textos inolvidables sobre ese fenómeno. El es el autor de la Crítica de la Razón Pura, pero su razón no era tan pura como para no dejarse ensuciar por la Revolución Francesa y, por lo tanto, por el drama fundamental de su época. ¿De qué no habla Hegel? (,Acaso no saluda la Revolución Francesa? El tiene una Lógica -un mamotreto- y también una Fenomenología del Espíritu en la que habla en cierto modo, de todo. El es un filósofo, ¿quién lo negaría? Es un filósofo, además, de oficio de cátedra en Jena, después en Berlín. Pero Hegel no puede ser indiferente. Recuérdese a Spinoza. Está su Ética que trata curiosamente de encontrar alguna formulación geométrica -por lo menos estilís ticamente, desde luego las deducciones no son geométricas- pero también es tá su tratado teológico-político que es uno de los antecedentes máximos de toda teoría de la democracia.

Los ejemplos abundan en ese sentido. Incluso un filósofo que no parece preocuparse más que por la pregunta sobre el sentido del Ser en general y sobre el olvido del Ser, como lo es Heidegger, que pretendía estar leyendo no se durante cuántos años, sesenta creo, los presocráticos. Pero se ve obligado a escribir su 
ensayo sobre la técnica, su Carta sobre el Humanismo. Intervino, a veces trágicamente equivocado, en política. A veces rectificando esas lamentables equivocaciones que al parecer fueron pocas. Tome a Jusserl que parece ser un filósofo tan puro; pero Husserl es un hombre preocupadísimo. La crisis de la humanidad europea es uno de sus últimos trabajos en donde está pensando concretamente el drama de la his toria que vive.

El filósofo no es un especialista $y$, mucho menos, un especialista en ideas í enerales. El filósofo ha sido siempre un interventor.

\section{PERO EN NUESTRO PAJS LOS FILOSOFOS SE HAN DESTACADO PRECISAMENTE POR NO SER INTERVENTORES....}

Ocurre por desgracia. A veces están muy determinados por el oficio de profesores de filosofía, lo que los conduce a la especialización de un tema muy circuns crito y a tratar de agotarlo. Por ejemplo, La Crítica de la Razón Pura o parte de este libro. O la Fenomenología del Espíritu de Hegel. O, digamos, un tema de filosofía analítica anglosajona. $\mathrm{O}$, en fin, cualquier tema circunscrito. Pero yo los llamaría más que filósofos, profesores de filosofía. Esos sí se pueden especializar y siempre tienden a hacerlo. Pero ese es un camino de facilidad tratar de dominar algún cieno tema y transmitirlo, lo que en el se va produciendo sin compromiso personal.

El filósofo ha sido siempre comprometido. Porque hay en la filosofía una aspiración fallida. No quiero decir una ilusión. Es más bien lo que Kant llamaría un ideal, el ideal de la universalidad, de que sus ideas son válidas en general y no sólo para su punto de vista o sus intereses. Si no, no es filósofo. Eso lo sabemos desde el Teetetos de Platón hasta hoy. La tendencia a la universalidad, la búsqueda, una búsqueda que es un ideal, no que se vaya a alcanzar o se haya alcanzado. Un ideal no es una quimera.

\section{ESTADO Y DERECHOS HUMANOS}

\section{¿COMO EXPLICA LA RELACION DEL ESTADO CON LA SITUACION DE DESEQUILIBRIO SOCIAL EXISTENTE?}

El nuevo fenómeno histórico que ponen de manifiesto los Derechos Humanos es y del que debió ocuparse Marx en lugar de ponerse a hacer una crítica puramente ideológica del utilitarismo y del sensalismo y del individuo propietario, en el cine estaba envuelto un hecho his tórico efectivamente nuevo que sí es este- que nadie ocupa el poder por derecho propio ni de nacimiento, ni de casta, ni por ningún motivo que le de un derecho propio de clase, pues, en principio, solamente lo ocupa por delegación y ese poder es un empleo que desempeña es un mandato que puede ser revocado, que es revocable o que, en todo caso, está circunscrito a un período y no se confunde nunca con su ser El peligro, por ejemplo, de tina formación como la staliniana, es que un partido declare tener la verdad de la 
historia en el bolsillo y ocupar el poder por derecho propio, irrevocable y que, además, se desborde sobre todos los aspectos de la vida social, de la sociedad civil. Decía ya Hegel que el poder se confunde con la verdad y se puede llegar al grotesco acontecimiento cine conocemos, o sea, que el poder ya no solamente legisle en términos mas o menos generales de las relaciones interhumanas, sino que diga como se pinta y cómo no se pinta, y cómo se hace música y qué es la ciencia, y cuál es la biología, y, bueno, etc., todo desde el poder. El poder confundido con el saber es una tragedia.

La defensa de los derechos humanos es muy importante en Colombia. Nosotros tenemos una cultura. Actualmente, por ejemplo, estamos padeciendo un conjunto de fenómenos y, a veces tino puede preguntarse ¿por qué Colombia es el amo del narcotráfico?, ¿por qué es uno de los países mas violentos del mundo?; ¿por que es el país de las masacres?; ¿por qué las guerrillas que se extinguieron como por sí mismas casi en toda Latinoamérica, en Colombia están muy lejos de encontrarse en extinción? .Se han debilitado políticamente pero se han fortalecido militarmente. $Y$ no hay más que razones sociales e históricas. No se puede encontrar una razón geográfica porque en ese caso para el narcotráfico estaría mejor situado México o Centroamérica y, sobre todo, un mejor sitio que Antioquia, donde es dificilísimo hacer una pista clandestina.

\section{Y ¿QUE TIENE ESTO QUE VER CON LARESPONSABILIDAD DEL ESTADO?}

Nosotros estamos padeciendo desde hace bastante tiempo de tina debilidad endémica del Estado. Yo soy partidario de un Estado fuerte lo que no requiere decir un Estado dictatorial sino todo lo contrario. Cuando pienso en un estado fuerte estoy pensando por ejemplo en Suecia o, digamos, en Francia. A ningún general francés se le ocurriría hacerle objeciones a una ley de Miterrand aunque Miterrand sea socialista. Pero no es que el ejército francés sea muy buena gente y el nuestro mala gente, sino que están en situaciones distintas.

Cuando el ejército francés estuvo en Argelia se manejó bastante peor que el nuestro. Un ejercito sumergido en un conflicto es muy difícil de controlar. Incluso por su propia cultura militar, aunque tuviera la voluntad de hacerlo. Y, más aún, por las sociedades, por un gobierno civil. Esa debilidad del Estado no quiere decir que el sea democrático o dictatorial. Debilidad del Estado quiere decir poder de otros focos que pueden ser los gamonales de provincia, los terratenientes, los gremios, los grupos amados, los paramilitares, lo que desborda al Estado y no se acoge a la ley estatal, a la justicia estatal.

Un es tado dictatorial puede ser igualmente un Estado extraordinariamente débil, tan débil como lo fue el de Laureano Gómez que finalmente lo descartaron en medio de un golpe que unos llaman militar y otros llaman de opinión, porque todo el mundo acogió el golpe. O como fue el de Rojas Pinilla que nunca logró organizar ningún modelo de sociedad y que fue destituido prácticamente en un "carnaval". Esos son es tados débiles. Precisamente el Estado débil no quiere decir que sea muy liberal, muy democrático. Quiere decir todo lo contrario: que no 
controla. El Estado mexicano, por ejemplo, fue el Estado más débil entre los años 1911 y 1936, pues era Pancho Villa en una parte y en otra parte el otro. No se sabía quién gobernaba. El Estado se fortaleció con Lázaro Cárdenas, pero con medidas: la nacionalización del petróleo, la nacionalización de los ferrocarriles, el repartir 17 millones de hectáreas en Refoma Agraria, y el echarse al bolsillo los sindicatos. Se volvió un Estado muy fuerte que después degeneró en un partido único que vuelve a ser un Estado débil. Es decir, quiero dar estos rodeos para que no se equivoque nadie cuando me quejo de la debilidad del Estado colombiano. Si yo quisiera un Estado fuerte, fuera más militarista. No. Todo lo contrario. Los Estados totalitarios son tan débiles cine le tienen miedo has ta a un pintor que pinte distinto. Hasta a un poeta meten a la cárcel. Un Estado fuerte es un Estado en el que el ciudadano puede estar tranquilo cuando esté en desacuerdo con el y, sin embargo, estando en desacuerdo con el gobierno, con el Estado, que apele a su normatividad para los debates que tiene en la vida civil. Es decir, que abra un espacio para que las diferencias de intereses puedan debatirse en la legalidad sin pasar a la violencia. Ese sí es un Estado fuerte.

USTED HA DICHO QUE EL DERECHO FUNDAMENTAL ES EL DERECHO A SER DIFERENTE. EN ESE SENTIDO...

Sí claro, pero eso no es mío. Creo que eso había sido dicho ya como una advertencia a Lenín por Rosa Luxemburgo. Que no se fuera a convertir esto en un estado gendarme -ra una advertencia casi profética - que no se fuera a repetir la experiencia de los jacobinos, que a nombre de ideales tan altos habían teminado en el terror. Pero la diferencia debe ser, y ese es el punto que a mí me interesa subrayar, apreciada por sí misma y no simplemente aceptada como una necesidad inevitable ya que los hombres no pueden ser unánimes ni marcar la misma hora como los relojes. Entonces, es mejor ser tolerante con las ideas de los demás y aprender a convivir en la diferencia.

En esto la posición filosófica tiene que ser un adversario del que no quiere convencer sino solo vencer. $Y$ tiene que aprender a ser un adversario eficaz. Es decir, estudiar a su país y ver qué posibilidades habrían de ampliar la democracia, de hacerla más participativa. No puede darse el lujo de serle indiferente vivir en un medio ambiente del que está rodeado, en el que nadie quiere convencer a nadie sino sólo vencerlo, liquidarlo, desaparecerlo y negarlo.

\section{VIOLENCIA Y MEDIOS MASIVOS DE COMUNICACION}

CON RELACION A LA VIOLENCIA, ¿CUAL CREE USTED QUE SEA LA RESPONSABILIDAD DE LOS MEDIOS MASIVOS DE COMENICACION?

Bueno, yo digo que los medios han fomentado la violencia mucho más en una forma indirecta que en una forma directa. Es decir, no es tanto porque presentan escenas violentas o porque presentan héroes que obtienen siempre la victoria por medios violentos. Eso puede influir no se has ta qué punto ni en qué medida; pero 
es sobre todo porque presentan el éxito y el consumo como el último fin de la vida. Cuando usted prende la televisión viene el bombardeo que le indica que su felicidad está en consumir algo, en comprar algo. Si usted se unta una loción las mujeres van a volar y el amor entonces es una cuestión de tener con qué comprarlo. El éxito en el amor entonces es una cuestión de tener con qué comprarlo. El éxito en el amor, el éxito en la sexualidad, el éxito en las relaciones humanas, la imagen de sí, la identidad, todo se compra y, entonces, el dinero es el dios, consígase como se consiga porque a uno no le preguntan los vendedores cómo lo consiguió.

Entonces, no es el esfuerzo, la victoria sobre sí mismo, sobre una dificultad. No es el resultado de un trabajo que se expresa en una obra, en un cuadro, en una composición musical. No es la lucha contra las propias dificultades, inhibiciones, represiones, lo que se considera que puede valorar la vida, sino el hecho de comprar algo. Eso, desde el punto de vista ético, es tal vez más dañino como mensaje que todas las escenas en las que aparecen peleando karate o a bala o a puños en los oestes norteamericanos y en todos estos enlatados y demás. Aunque no digo que eso no sea muy conveniente. No se. Pero me parece que se ha exagerado mucho el análisis inmediato. Se ha llegado a un punto de autocensura en el cual se trata de presentar un país ideal, un país de familias idealizadas y de parejas idealizadas, en medio de una crisis realmente monstruosa y esa mentira no arregla nada. La política del avestruz que mientras entierra la cabeza lo despluman por detrás. Es la política de la televisión que al mismo tiempo cine descompone toda valoración ética en, por ejemplo, la posibilidad que tengan los niños o los jóvenes o los adultos de valorar las personas, convierte en valores absolutos lo impuesto por el consumo.

En ese sentido, lo negativo es la desculturización que genera y la descomposición ética que va implícita en el mensaje de que "el consumo es aquello de lo que se puede esperar la felicidad". Eso es propaganda a la droga, aunque después adviertan que la droga hace daño al cerebro. Pero ese es un consumo que cambia la sensación del mundo. Ahí lo están haciendo. Ahí le están dando un mensaje permanente a la juventud de que comprando algo va a cambiar la impresión que ella tiene de sí misma y del mundo. Por ejemplo, cocaína o marihuana. Esos son consumos que cambian la impresión que el hombre tiene de sí mismo, en lugar de conquistar una nueva identidad por los trabajos que ha logrado hacer, en el fondo lo que cuenta es conseguir la plata como sea, pues el esfuerzo no está valorado sino el consumo y hay que consumir.

Lo único que diferencia a los hombres entre sí, según el mensaje de la publicidad, es aquello que compran. Y si lo único que diferencia y lo que abre las puertas al amor, a la felicidad, a la realización, es el consumo; entonces el dinero es Dios. El dinero es la Puta universal, como diría Marx citando a Shakespeare. Esa es la prédica permanente. 